\title{
THE CHALLENGES, ROLES AND FUNCTIONS OF CIVIL MILITARY COORDINATION OFFICERS IN PEACE SUPPORT OPERATIONS: A THEORETICAL DISCUSSION
}

\author{
Gary Lloyd and Gielie van Dyk \\ Department of Industrial Psychology, Faculty of Military \\ Science, Stellenbosch University
}

\begin{abstract}
The introduction of a multidimensional approach towards peace missions in complex emergencies emphasises the importance of coordination between the military and the humanitarian components at all levels of interaction. Cooperation and coordination between the military and humanitarian components are critical to achieve a common goal to alleviate suffering and to save lives. The challenge is how to develop, enhance and sustain an effective working relationship to overcome the conflicting views on coordination from the military and humanitarian perspectives. Humanitarians fear the loss of independence and neutrality when associated with the military when the military component becomes directly involved in humanitarian action. During selection, the military needs to identify members who firstly conform to the generic psychological peacekeeping profile and secondly portray the skills, knowledge and abilities to perform the coordination function between the military and the humanitarian component. The challenge remains to select competent military members in the absence of a psychological profile for the coordination function. This article paves the way for research on the psychological profile for a civil military coordination officer (CIMIC officer), highlighting the importance of coordination through analysing the environment, challenges and perspectives in defining the roles and functions of CIMIC officers in complex emergencies.
\end{abstract}

\section{Introduction}

Challenges in cooperation and coordination between the military and humanitarian components in peace missions are well-documented phenomena (George, 2002; Jenny, 2001; Pugh, 2001; Spence, 2002). These challenges are in excess of the normal challenges and stressors experienced by peacekeeping soldiers. Although the concepts are clearly defined in the military and humanitarian 
components, the challenge remains in creating effective mechanisms to enhance cooperation and coordination.

This theoretical discussion paves the way for research on the psychological profile for selection of civil military coordination (CIMIC) officers. The research was conducted by means of a cross-sectional study over a period of 14 months. It was conducted within the framework of a qualitative exploratory field research design with an institutional ethnographical paradigm. The design was applied within the African Mission in the Sudan (AMIS) to determine the extent of the challenges that a CIMIC officer experiences. The study was conducted in two phases. The researcher conducted field research during phase 1. During this phase, primary and secondary data were gathered through interviewing, observations and analysing documentation. The researcher analysed peace support operations (PSO), PSO stressors and the civil military coordination (CIMIC) environment from a humanitarian and military perspective to define the roles and functions of a civil military coordination (CIMIC) officer. In phase 2 , the data were integrated into a psychological profile by means of competency modelling. This model encompasses the roles, functions environmental challenges and behaviours of CIMIC officers. The competency model comprises of positive behavioural indicators that enhance coordination in the execution of the roles and functions of the CIMIC officer. In this article, the theoretical foundations based on the challenges of the peace support operations environment, the stressors for peace support soldiers, civil military coordination and the roles and functions of the CIMIC officer are discussed.

\section{Peace support operations}

'Peace support operations' is the umbrella term describing military involvement in all types of peace missions (Hough, Du Plessis \& Kruys, 2006). Bruwer (2003) indicated that the South African Department of Defence (DoD) identified preventative diplomacy, peacemaking, peacekeeping, peace enforcement, peacebuilding and humanitarian or relief activities as relevant for future participation. The discussion on these types of operations and challenges in a theoretical framework emphasises the challenging working environment of the CIMIC officer. Some of these concepts need clarification:

- Preventative diplomacy. "Action to prevent disputes from arising between parties, to prevent existing disputes from escalating into conflicts and to limit the spread of the latter when they occur" (Hough et al., 2006, p. 21). Politicians facilitate this intervention with the military contributing in a supporting role when requested. 
- $\quad$ Peacemaking. Kofi Annan (in Aning, Addo, Birikorang \& Sowatey, 2004, p. 12) defined peacemaking as "the use of diplomatic means to persuade parties in a conflict to cease hostilities and to negotiate a peaceful settlement of the dispute". Efforts to achieve peacemaking include a process of diplomacy, mediation, negotiations or other forms of peaceful settlement of conflict. Military forces may be required to support the process.

- $\quad$ Peacekeeping. "Peacekeeping is the deployment of a United Nations presence in the field, hitherto with the consent of all parties concerned, normally involving United Nations military and/or police personnel and frequently civilians as well. Peacekeeping is a technique that expands the possibilities of both the prevention of conflict and the making of peace" (Hough et al., 2006, p. 21).

- Peace enforcement. Bruwer (2003) described peace enforcement as the application or threat of military force with the aim to maintain/restore peace and to support diplomatic efforts in order to achieve a long-term settlement.

- Peacebuilding. Peacebuilding is defined in the 1996 South African White Paper on Defence as "peacebuilding may occur at any stage of the conflict cycle, but is critical in the aftermath of the conflict. Peacebuilding includes activities such as the identification and support of measures and structures that will promote peace and build trust, and the facilitation of interaction among former enemies in order to prevent a relapse into conflict" (Williams, 1999, p. 169).

Peacebuilding unfolds through a phased approach once hostilities have ceased and includes a broad scope of programmes addressing short- to long-term roots and consequences of conflict. Peacebuilding is implemented in three phases, namely stabilisation, transition and consolidation with five broad frameworks within each phase, including security, political transformation, economical reform, human rights and judicial reform, coordination, management and resource mobilisation (De Coning, 2005). De Coning (2005) said that the coordination, management and mobilisation phases are critical for the successful implementation of all the peacebuilding dimensions. This aspect highlights the importance of this study to select a competent officer for this critical task.

\section{Multidimensional peacekeeping}

Multidimensional peacekeeping is differentiated by the fact that the military interacts with other mission components. Interaction with political components results 
in the adjustment of military tasks to address political realities. The military interacts with the administrative and support components on joint logistics and supply. Coordination is essential with other components for humanitarian activities, human rights monitoring, civil affairs and restoration of law and order. The following mechanisms can be found where the CIMIC officer enhances the coordination process (United Nations Department of Peacekeeping Operations [UN DPKO] 2003):

- $\quad$ strategic planning and coordinating component inclusive of military experts;

- an integrated joint operation centre to coordinate daily activities, including military, political, civil affairs, human rights, public information and other mission components; and

- an integrated civil military coordination component to coordinate activities with other civilian actors in the mission. This component facilitates information sharing, mutual support, joint assessments, integrated planning and common strategies.

\section{Complex emergencies}

The Inter-Agency Standing Committee (IASC) defines a complex emergency as "a humanitarian crises in a country, region or society where there is total or considerable breakdown of authority resulting from internal or external conflict and which requires an international response that goes beyond the capacity of a single and/or ongoing UN country programme" (Inter-Agency Standing Committee [IASC], 2005, p. 5). The definition of Salama, Spiegel, Talley and Waldman (2004, p. 1801) does not include natural disasters. These authors define a complex emergency as "the situation in which mortality among the civilian population substantially increases above the population baseline, either as a result of direct effects of war or indirectly through increased prevalence of malnutrition and/or transmission of communicable diseases, particularly if the latter results from deliberate political and military policies and strategies".

Complex emergencies are characterised by:

- a deteriorating or total disintegration of central government authority;

- ethnic or religious conflict accompanied by extensive human rights violations;

- mass starvation as a result of sporadic food insecurity;

- weakening or collapse of economic systems resulting in a decrease in the gross domestic product and substantial unemployment; 
- mass movement of displaced populations as internally displaced persons or refugees in search of food and security; and

- war and decreased commitment to development.

This instability frequently overflows into neighbouring counties that are often unstable themselves (Knuth, 1999; Natsios, 1995). Power-hunger individuals, at the cost of many other individuals, shape this situation of enduring insecurity. These actions are characterised by human rights violations and the destruction of economic and social structures (Lautze, Learning, Raven-Roberts, Kent \& Mazurana, 2004).

\section{A theoretical framework for peace support operations}

Peacekeeping evolved from traditional peacekeeping that focuses primarily on a military model of observing buffer zones, monitoring cease-fire agreements and supporting disarmament plans subsequent to interstate wars, to a multifaceted model where civilians and the military coexist to build peace in the hazardous aftermath of civil wars (Durch, Holt, Earle \& Shanahan, 2003; Mohamed, 2005). Mohamed (2005) identified consent of the parties, neutrality of the peacekeepers and minimum use of force, generally only for the purpose of self-defence, as the key principles for an intervention within the framework of traditional peacekeeping.

The limitations of traditional peacekeeping principles were exposed in operations characterised by limited consent in the grey area between traditional peacekeeping and peace enforcement. Jakobsen (2000) referred to the British approach to grey area operations (complex emergencies) where the military component conducts its mission by means of prevention, negotiation and consentpromoting techniques, but where it will also use limited force if required to protect the population and the mandate. The objective remains not to defeat the parties but to create conditions for a stable peace settlement (Jakobsen, 2000). The Brahimi report urged the UN to revise its doctrine and strategy on peacekeeping and to develop an enhanced strategy for peacebuilding in complex emergencies. A critical success factor for implementing the revised strategies is the implementation at grass roots level in the field to ensure effective complex peace operations (Durch et al., 2003)

The initial response models to complex emergencies were based on models of emergency relief in natural disasters. These models did not address the transition from a phase of conflict into a rehabilitation and development phase (Lautze et al., 2004). Cilliers and Mills (1999) indicated that complex missions, which involve concurrent political, military and humanitarian intervention, have their foundation in traditional peacekeeping experiences. Salama et al (2004) identified the longer period 
of complex emergencies as one of the main reasons for the need for a significant shift in approach towards peacekeeping. The military's partnership with civil society in peacebuilding is in most instances not an opinion but an absolute necessity (Keating \& Knight, 2004). It highlights the importance of coordination and cooperation between the military, humanitarian and civilian components. Williams (1999) argued that the definition of peacebuilding does not indicate the role players or the duration of peacebuilding. Without a clear definition the formulation of a clear aim, allocation of resources, realistic time frames and the establishment of coordination mechanisms remain a challenge.

The New Partnership for Africa's Development (NEPAD) underlined the focus of the African continent that Africa should address Africa's challenges (Heyns, 2005). Irrespective of this viewpoint, Rotberg, Albaugh, Bonyongwe, Clapham, Herbst and Metz (2000, p. 107) said: "African problems could not be left exclusively to Africans, the gross violations of human rights occurring in parts of Africa demand the resources and attention of the whole world." During a high-level South African Development Community (SADC) visit to Denmark in 1998, it was emphasised that Africans should take ownership of peacekeeping in Africa by maintaining command, control and communications of peacekeeping operations, inclusive of training in Africa. The absence of adequate and effective capabilities and resources in these areas will impact negatively on the ability of African forces to conduct operations without foreign assistance (Rotberg et al., 2000). Insufficient funding of the African Union (AU) has a negative impact on its ability to mount effective operations and subsequently the concept of a hybrid force has been accepted where the UN provides expertise and resources, although it is clearly stated that the leadership must remain African. The reality is that African peacekeeping will remain underfunded and that UN resources remain insufficient to match the African requirements (Cilliers \& Mills, 1999). Subsequently the vision of more resources for peacekeeping in Africa remains inadequate.

The lack of resources emphasises the importance of optimal utilisation of available resources. The shortage of resources highlights the importance of this study where CIMIC officers, selected according to a psychological profile, would ensure that the resources are directed towards the most suitable candidates. The definition for this study is formulated within the multidimensional approach to complex emergencies, within which CIMIC officers function. The roles of CIMIC officers are not limited to a specific peace mission. With this definition (as stated below), the researchers intend to orientate the reader towards the complexities of emergencies and the diverse and challenging environment within which CIMIC officers perform their duties. 
Peace support operations are defined as actions to prevent conflict (Hough et al. 2006), to cease hostilities and negotiate peaceful settlements (Aning et al., 2004), to implement and monitor agreements and restore peace (Bruwer, 2003), to address consequences of the conflict (De Coning, 2005) and to construct an enduring peaceful resolution (Keating \& Knight, 2004).

CIMIC officers have to cope with and adjust to the ever-changing and dynamic PSO environment as discussed above. To perform the CIMIC roles and functions efficiently, the CIMIC officer must be emotionally stable to adjust to and cope with the multitude of generic PSO environmental stressors.

\section{Peace support environmental challenges}

It is essential to analyse the impact of the environmental stressors on individual soldiers during deployment in complex emergencies. There is a general misconception that the nature of peace missions involves less risk and exposure to potentially traumatic events than the traditional war zone. Analysis of the physical and psychological stressors in peace missions indicated that it could result in severe and enduring psychiatric impairment (Orsillo, Roemer, Litz, Ehlich \& Freidman, 1998). The multitude of peacekeeping environment challenges are discussed below as physical, cognitive, emotional and social stressors.

\section{Physical stressors}

During operations, peacekeepers are confronted with various dangers during patrols and monitoring. These dangers include units being fired upon, rocks being thrown at units (Litz, 2004; Michel, 2005; Orsillo et al., 1998), shootings not directed at the soldiers (Bramsen, Dirkzwager \& Van der Ploeg, 2000), verbal abuse and harassment by civilians (Bolton, 2005), locating unexploded landmines and patrolling in those mined areas (Litz, 2004), soldiers being challenged at gunpoint outside their camps (Rosebush, 1998), confrontations at checkpoints and shelling of camps (Deahl, Srinivasan, Jones, Thomas, Nebrett \& Jolly, 2000; Vogelaar, Soeters \& Born, 1997).

The working conditions during peace operations are associated with long hours and low intensity of operations, especially during the initial phases of the operation (Bartone, 1997; Bruwer, 2003; Stanley, 2003; Van Dyk, 1998), double standards for ranks and insufficient equipment (Rosebush, 1998), while unpredictable work schedules, dissatisfaction with superiors and an inability to get along with other nations in the contingent are related to stressors (Stanley, 2003). Bruwer (2003) 
identified long meetings and a high frequency of meetings, micro management of leader group and sleep deprivation as major stressors. Living conditions include crowded and confined living quarters, lack of privacy, poor facilities for leisure and physical exercise (Bruwer, 2003; Stanley, 2003) and poor sanitation of latrines and living areas (Bruwer, 2003). Peacekeepers are exposed to extreme weather conditions although this was only recorded as a possible stressor in the UN Mission in the Democratic Republic of the Congo (MONUC) (Bruwer, 2003).

\section{Cognitive stressors}

The main cognitive stressor for peacekeepers relates to role conflict. Soldiers are trained psychologically and technically to defeat enemies, implying a different mental mindset than that required during peace missions. During peace missions, the role conflict is based on the neutral mindset of war trained soldiers and the ambiguity concerning taking the right decision within a peace mission framework (Orsillo et al., 1998; Shigemura \& Nomura, 2002). The physical environment influences the role ambiguity and can result in cognitive stressors. The following challenges can result in cognitive stressors.

Ambiguity. Peacekeeping soldiers continuously question actions within the peace mission environment based on an ambiguous mandate. An ambiguous mandate is subject to different interpretations. Different interpretations result in commandstructure confusion, doubts about the value of the mission, an unclear end state, mission creep, doubt related to the significance of the role that the peacekeeper plays in the mission, and doubt about the length of the mission related to when the end state will be achieved (Bartone, 1997; Bartone \& Adler, 1994; Nuciari, 2002; Rosebush, 1998; Shigemura \& Nomura, 2002). Doubts with regard to the significance of the peacekeepers' role are influenced by aspects like why peacekeepers have to remain neutral and restricted with regard to the use of weapons when mass rape, ethnic cleansing and massacres are taking place and war criminals are not arrested (Litz, 2004; Shigemura \& Nomura, 2002).

Danger and threat. The escalation of threat and danger is unpredictable. Peacekeepers experience the fear of political consequences for their actions. This challenge is complicated by the ambiguity and restrictive nature of rules of engagement. Peacekeepers are often confronted and humiliated by civilians and parties to the conflict, attacked by civilians and militia and are sometimes viewed as an opposing force. Peacekeepers have to tolerate these challenges since the rules of engagement often restrict them from retaliating or taking offensive actions (Shigemura \& Nomura, 2002). Peacekeepers frequently ask the question as to why they should endanger their 
lives by operating in a volatile environment when the local population does not appreciate their efforts (Bramsen et al., 2000).

Boredom and monotony. Peacekeepers are trained professional soldiers who thrive on challenges to display their professional capabilities. Peacekeeping soldiers are employed in simple and repetitive tasks. This results in monotony and boredom that leads to loss of mission focus (Bartone, 1997; Bartone \& Adler, 1994; Bolton, 2005; Bruwer, 2003; Nuciari, 2002).

Career anxiety. Bartone (1997) indicated that the loss of educational opportunities, lack of advancement opportunities, financial problems and problems with unit leaders, impact on career anxiety. Peacekeepers are concerned that their career managers will overlook them during deployment (Stanley, 2003).

\section{Emotional stressors}

Peacekeepers who are confronted with death and destruction of a great magnitude have the potential to develop emotional, physical, cognitive or behavioural symptoms of distress. Peacekeepers have to adjust to death and extreme human suffering on a daily basis. Stressors related to exposure to death are not restricted to death of a comrade, but also includes seeing human remains, witnessing civilian deaths, observing atrocities against locals and witnessing injuries to locals that result from mines or belligerent attacks (Bramsen et al., 2000; Deahl et al., 2000; Litz, 2004; Orsillo et al., 1998; Rosebush, 1998; Shigemura \& Nomura, 2002; Vogelaar et al., 1997).

Feelings of powerlessness in peacekeepers impact on emotional stressors. Peacekeepers observe the suffering of the local population and have little means due to a restrictive mandate to alleviate suffering or to improve safety (Bolton, 2005; Bramsen et al., 2000; Shigemura \& Nomura, 2002). The inability of the peacekeepers to address this suffering reflects negatively on the UN system that impacts on emotional stressors based on the ambiguity of the mission and role conflict (Rosebush, 1998).

\section{Social stressors}

Research indicated that social stressors are more prominent during the establishment of a mission and the first few months of its operations (Bruwer, 2003; Vogelaar et al., 1997). Prominent social stressors during the initial phases include: 
- Insufficient time for the planning staff to finalise personal business and to prepare families for deployment. This is due to involvement in an extensive planning cycle before deployment (Bartone, 1997).

- Other initial stressors include isolation from families due to the time frame linked to the establishment of communication support systems (Shigemura \& Nomura, 2002), financial concerns, separation from families and friends and lack of family support (Bartone, 1997; Bruwer, 2003; Litz, 2004; Nuciari, 2002). Stanley (2003) reported that the impact of leaving a newborn baby behind increases the impact of family well-being as a social stressor. Isolation remains prominent throughout the mission as a possible stressor stemming from feelings of being forgotten. These feelings are enhanced by a lack of media recognition, little recognition from commanders, lack of appreciation from the host country and lack of recognition from home (Bruwer, 2003; Shigemura \& Nomura, 2002; Stanley, 2003).

The importance of an emotionally stable CIMIC officer is critical to enable the individual to adjust to and cope with the multitude of PSO stressors (Kets de Vries \& Miller, 1986; Van Dyk, 1998). Furnham and Taylor (2004) reported that individuals who are emotionally unstable would display counterproductive behaviour due to their inability to adjust to stressful environments. CIMIC officers with a balanced personality (Hall, Lindzey \& Campbell, 1998), high self-esteem (Van Dyk, 1998) and high internal locus of control (Horey, Fallesen, Morath, Cronin, Cassella, Franks \& Smith, 2004) should be able to adjust to and cope with the challenging PSO environment.

\section{The concept of civil military coordination}

The Office of Internal Oversight Services (OIOS) reported that the increase in military involvement in civil assistance (MICA), complementary to the primary military role of providing security, is due to the realities of conflicts and the shift towards broader peacekeeping mandates within the context of multidimensional peacekeeping (Office of Internal Oversight Services [OIOS] 2005). The IASC emphasised that the military and humanitarian components have fundamentally different ways of institutional thinking and organisational cultures. The humanitarian community is more diverse compared to a well-structured hierarchical chain of command of the military component (IASC, 2005).

Various challenges and many suggestions have been developed and implemented following on lessons learned in peace support operations. Challenges 
continue to exist with regard to coordinating the humanitarian and military activities at grass roots level. Abiew (2003) avers that these problems exist due to ad hoc improvements made at grass roots level and often influenced by personal views of field workers. The Brahimi report provides the strategic direction with specific focus on the improvement of humanitarian coordination, but the challenge remains. Even though the UN claims to have a strategic plan for coordination during complex emergencies, few relief agencies wish to be coordinated with or to comply with a single strategy, especially those in the field (Natsios, 1995). Notwithstanding, some uncertainty remains and need to be clarified. Hence, some definitions, role players, humanitarian and military points of view and measures to enhance coordination are discussed in the section below.

\section{Definitions}

Coordination is a critical aspect in complex peace support operations. It remains the most important mechanism to create synergy and to achieve common goals during the peace, security and development phases (De Coning, 2005). It is imperative to have a thorough understanding of the complexity of the concept of CIMIC as theoretical foundation for the psychological profile of a successful CIMIC officer.

Peace support operations literature reveals that there are various definitions for the term "civil military coordination" and the challenge remains to find a universally accepted definition for the relationship between the military and the humanitarian component. According to Pugh (2001), the reason for divergence in interpretation is due to the different purpose and focus of the humanitarian and military components. The researchers highlight the complexity and dynamics of the civil military coordination environment by discussing a number of definitions.

The United Nations Department of Peacekeeping Operations (UN DPKO). The UN DPKO refers to the civil-military relationship as "United Nations CivilMilitary Coordination". This relationship is described as a system of interaction, involving exchange of information, negotiation, de-confliction, mutual support, and planning at all levels between military elements, humanitarian organisations and civilian population to achieve respective objectives (United Nations Department of Peacekeeping Operations [UN DPKO] 2002). Communication, planning, interpersonal and negotiation skills are central to the UN CIMIC definition. Although defined in a policy document, this definition is not universally accepted throughout the UN system. The Office for Coordination of Humanitarian Affairs (OCHA), a component of the UN System, defined CIMIC from a humanitarian perspective. (The 
OCHA definition is discussed in the following paragraph.) De Coning (2005), however, suggested the use of the acronym "UN CIMIC" to distinguish between UN and other CIMIC definitions.

The United Nations Office for the Coordination of Humanitarian Affairs (OCHA). The United Nations Office for the Coordination of Humanitarian Affairs (OCHA) (2004) described civil military coordination from a humanitarian perspective as the essential dialogue and interaction between civilian and military actors in humanitarian emergencies that are necessary to protect and promote humanitarian principles, to avoid competition, minimise inconsistency and when appropriate to pursue common goals. Basic coordination strategies range from coexistence to cooperation on the spectrum of conflict. Coordination is a shared responsibility facilitated by liaison and common training by the humanitarian and military components. This calls for members to work in joint teams, define strategic integrated plans, set common goals and be accommodating. OCHA uses the acronym "CM Coord" to distinguish their definition from that of the military perspective (OCHA, 2004).

North Atlantic Treaty Organisation (NATO). Although not part of the UN System, the NATO acronym, "CIMIC", is unofficially used in most peace missions. From a military perspective, NATO defined the relationship as "the coordination and cooperation, in support of the mission, between the NATO Commander and civil populations, including national and local authorities, as well as international, national and nongovernmental organisations (NGOs) and agencies" (Jenkins, 2003, p. 129; Rollins, 2001, p. 123). The NATO focus is upon on a military approach where superior analytic, decision-making and planning skills are essential. This definition for CIMIC is NATO-specific and it is not universally accepted throughout by all military and humanitarian components.

United States Military. The United States (US) Civil Affairs (CA) doctrine addresses aspects of cooperation, coordination and activities to enhance the relationship between civilian and military components as well as support to civil military operations. CIMIC, in US Joint Doctrine, encompasses a wide spectrum of actions ranging from sustaining life to restoring governments. The US CIMIC definition refers to cooperation, rather than coordination. Activities to enhance the relationship include joint training, effective communication and respect for cultural diversity (African Centre for the Constructive Resolution of Disputes [ACCORD], 2005; Joint publication [JP], 2003; Pollick, 2000).

The South African DoD deploys peace mission forces under the auspices of the $\mathrm{UN}$ and the $\mathrm{AU}$. The AU adopted the approach that $\mathrm{UN}$ policies and guidelines 
form the foundation of $\mathrm{AU}$ policies and documentation. Derived from literature, the theme of cooperation and coordination is central to the definitions that address the relationship between the military and humanitarians. The challenge is to create synergy between the humanitarian and military views regarding the utilisation of the military in humanitarian tasks. De Coning (2005) emphasised the importance of a universally accepted definition for CIMIC as a central point of departure within the UN environment. This will reduce the diverse interpretations of the term in the international peacekeeping community. Since the South Africa operates within the UN System, and the AU adopted the abovementioned approach, the following UN DPKO definition for Civil Military Coordination (UN CIMIC) is accepted as definition for this study:

“. $\ldots$ as the system of interaction, involving exchange of information, negotiation, de-confliction, mutual support, and planning at all levels, between military elements, humanitarian organisations and civilian population to achieve respective objectives".

The following electives for a CIMIC Officer are derived from the definitions: superior analytic skills, decision-making skills, planning skills including goal setting, communication and liaison skills, training skills, teamwork and respect for cultural and organisational diversity. The international community recognises the fact that it is imperative to promote enhanced cooperation and coordination between the military and the humanitarian communities (Abiew, 2003). The terms "coordination" and "cooperation" are frequently applied in an inter-changeable way in CIMIC. It is therefore essential to define these terms within the concept of CIMIC to derive the electives for measurement of a successful CIMIC officer.

Definition of cooperation. Abiew (2003) perceived the term "cooperation" as a relatively weak concept for the military. Abiew (2003, p.33) referred to the British Military perspective, according to which "cooperation is more about consensus and heading together in an agreed direction than about strict coordination and command, to achieve a comprehensive approach based on complimentary capabilities". Thus, cooperation entails working together towards the same goals.

Definition of coordination. Abiew (2003, p. 33) defined coordination as "Bringing together into a proper or required relation to ensure harmony or effective cooperation". Cooperation becomes evident when common goals have been identified. Common goals are encompassed in an approved strategy on improving the effectiveness and efficiency of combined humanitarian objectives through coordination (IASC, 2005). De Coning (2005) distinguished three types of civil 
military coordination functions: liaison and information management, mission support and community support. He perceived the sharing of information as the core function of coordination.

\section{Role players}

To emphasise the holistic approach to this study, the researchers analyse the CIMIC environment from a humanitarian as well as military component perspective. IASC (2005) defined humanitarian actors as "civilians, whether national or international, UN or non-UN, governmental or non-governmental, which have a commitment to humanitarian principles and are engaged in humanitarian activities" (p. 5). Military actors are defined as "official military forces, for example military forces of a state or region-/inter-governmental organisation that are subject to a hierarchical chain of command, be they armed or unarmed, governmental or inter governmental. This may include a wide spectrum of actors such as the local or national military, multinational forces, UN peacekeeping troops, international military observers, foreign occupying forces, regional troops or other officially organised troops" (IASC, 2005, p. 5).

\section{A humanitarian view}

Burckle (2006) describes humanitarian assistance as support to the civilian population to prevent loss of life and to reduce the suffering of the crisis-affected populations. He regarded assistance as most effective when provided by civilian humanitarian agencies under UN leadership. Some humanitarians see interaction with the military as compromising to their security, impartiality and neutrality. These assumptions are frequently founded on previous individual experiences. The humanitarian component regards the presence of the military in protecting their assets as a possible threat to their personnel. The parties to the conflict can perceive aid workers as targets. The humanitarian community also has to weigh up the probable advantages of short-term cooperation with the military against potential consequences of long-term isolation. Humanitarians should maintain their neutrality long after the military component has withdrawn (Abiew, 2003; Burckle, 2006).

The humanitarian community shares information on the suffering of civilians. Humanitarian actors are reluctant to share other sensitive information with the military because of their perception that the military seeks information that is beyond the immediate crisis (Abiew, 2003). Pugh (1998) regards military involvement in humanitarian action as inherently political and the provision of security for humanitarians to be an excuse for a military intervention. De Coning 
(2005) disagreed with Pugh's (1998) view. He indicated that within the scope of UN peacebuilding operations both military and humanitarian components are perceived as credible and legitimate neutral parties. Therefore, the relationship between the military and humanitarian component can and should be more cooperative.

Coordination challenges are not restricted to the military and humanitarian components only; these challenges are also relevant within the humanitarian community (Reimann, 2006). There is lack of role definition among UN agencies escalating into ineffective competition for resources and control of emergencies. The consequences of poor coordination are not limited to ineffective utilisation of resources. Severe consequences may be the loss of lives due to a delay in response caused by discussions on role clarification and responsibilities (Lindenberg \& Bryant, 2001). Projects by NGOs are dependent on donor funding and subsequently some are more concerned with donor interest than with the needs of the crisis-affected population that they claim to serve (Reimann, 2006).

The humanitarian community performs its duties under the umbrella of three fundamental principles, namely humanity, neutrality and impartiality. The humanitarian component regards the compromising of these principles as the primary barrier limiting coordination between the military and humanitarian components. According to Seybolt (1996), the principle of uncompromising neutrality originated from the historical understanding of humanitarian emergencies caused by natural disasters. During a natural disaster, the government of the day remains in control. Furthermore, no harm is intended against the population and no noticeable barriers exist that prohibit cooperation and coordination between the military and humanitarian components. These barriers only exist in complex emergencies where the humanitarian component fears the loss of independence and neutrality when associated with the military.

The humanitarian component feels that the military becomes more directly involved in un-mandated humanitarian work (Jenny, 2001; Munslow \& Brown, 1999). Military components' involvement should have a short-term focus, be highly effective in terms of numbers deployed and should take place under a mandate with clear objectives. The military component secures the environment, protects humanitarian assets and personnel, provides humanitarian support activities including convoy escorts, humanitarian supplies and equipment transport as well as repair and maintenance of infrastructure. The humanitarian community weighs these advantages against their operating principles of neutrality and impartiality (Newland \& Meyers, 1999). Humanitarian actors express the need for clearly defined perimeters indicating procedures when considering military assistance in humanitarian tasks (Jenny, 2001). 
In response to this need, the OCHA drafted the IASC Reference Paper that serves as a non-binding reference document. This document provides the framework to assist in the formulation of country-specific guidelines on the use of military assets in humanitarian action during complex emergencies (OCHA, 2004).

Abiew (2003) reflected on the notion that humanitarians will not to be controlled or commanded by the military. Barriers obstructing coordination include unique organisational cultures, leadership styles, command and control, cost structures, decision-making authority and differences in time management. These barriers manifest in negative implications for attempts to facilitate a degree of cooperation (Abiew, 2003; Newland \& Meyers, 1999).

The humanitarian component strongly opposes community support initiatives by the military towards the local communities. The military aims to increase the confidence of local communities towards military action in the peace process. Humanitarian assistance by the military is based on available resources rather than population needs. Target populations are selected based on co-location and not by means of an independent need assessment involving the community and humanitarian components. These actions are often not life-saving assistance, nor are they motivated by the humanitarian principles of humanity, impartiality and neutrality (De Coning, 2005).

The humanitarian perspective highlights the importance of maintaining the principles of humanity, neutrality and impartiality. The need for coordination with the military within the perimeters of these principles is acknowledged. Role definition, clearly mandated tasks, deployment time frames, understanding organisational cultures, operating procedures and decision-making structures are the main barriers preventing effective coordination. The CIMIC officer can facilitate enhanced coordination through consultative and participative processes and awareness training to address the abovementioned barriers.

\section{A military view}

According to Pugh (2001), the military component is capable of performing humanitarian tasks. The question however remains whether the military is sufficiently capacitated to perform humanitarian and security task simultaneously. Jackson (2005) believes that the quality of the military component is crucial for humanitarian success. NATO identified the need for the military component to become involved in humanitarian and reconstruction activities. The Organisation adopted this approach on account of the unacceptable human suffering they observed as a result of mandated 
humanitarian organisations that are not effective in meeting the immediate need. The NATO approach is focused on filling the security vacuum as an interim arrangement. All tasks are transferred to applicable civil authority or humanitarian components as soon as they are operational. The withdrawal of the military component is delayed when the civilian population is not sufficiently empowered to maintain an acceptable human rights environment. To facilitate a seamless transition from the military to the humanitarian component, it is imperative to establish liaison between the military and the humanitarian component before deployment (Pugh, 2001).

Harris and Dombrowski (2002) identified physical protection of civilian personnel by armed military personnel as the central function in civil military coordination. Pugh (1998) agreed that the creation of a secure environment by the military component is essential for the humanitarian community to provide relief. The core competencies for the military's involvement in complex emergencies are:

- $\quad$ providing security for the relief operations;

- $\quad$ imposing negotiated agreements;

- $\quad$ providing security for non-combatants;

- $\quad$ employing logistical capabilities; and

- $\quad$ in extreme situations, requesting the military component to deliver food aid in areas of total insecurity (Burckle, 2006).

The military perspectives on civil military coordination are discussed within the framework of four categories: complimentary action and avoidance of duplication, command and control, mutual understanding and flexibility, and coordination at all levels.

Complementary action and avoidance of duplication. Effective resolution of conflict requires an approach where capabilities and capacity of various organisations complement one another. Hatzenbichler (2001) claimed that humanitarian assistance should be provided by the military component when such assistance complements the efforts of foreign governments and the humanitarian component to alleviate the suffering on account of manmade or natural disasters. Spence (2002) indicated the need for a holistic approach inclusive of clearly defined responsibilities, clear perimeters that allow for flexibility and provision for consultative processes. Through this process, new responsibilities are assigned to the relevant role players through negotiations. It is essential to define roles and responsibilities in order to avoid duplication of effort and to optimise available resources (Abiew, 2003). The military needs to be aware that the humanitarian component will only request support when 
the capability required is unique, civilians cannot provide the capability in a timely fashion and the use of the military capacity is a last resort (Pugh, 1998).

Command and control. Coordination does not imply a change in relation to command. The command channels of the military and humanitarian/development actors should be fully observed. A participative approach in analysing the root cause of the conflict results in a common understanding of the conflict and a focused approach. This approach is complicated by the complex chain of command within the humanitarian as well as the military components. Spence (2002) identified the sharing of information as a critical factor in determining what can be achieved, which task can be performed by whom and under what circumstances tasks will be performed. Jakobsen (2000) highlighted the importance of creating effective partnerships with humanitarian agencies and NGOs. These partnerships are based on mutual respect and coordination by consensus and not command. Superior negotiation and interpersonal skills are essential to enhance these partnerships.

Mutual understanding and flexibility. Emergency humanitarian assistance is provided within the framework of the principles of humanity, neutrality and impartiality. The military component should have a thorough understanding of these principles to avoid compromising humanitarian operations. Mutual acknowledgment of interdependence is crucial for successful implementation of coordinated operations. Mutual understanding provides a firm basis for a flexible approach towards complex mission issues (Pugh, 1998). Both components should acknowledge that joint action results in a loss of autonomy on both sides. A coordinated approach ensures that a joint assessment is conducted to identify key tasks, to assess available resources and draft integrated plans and to establish coordination mechanisms (Cockell, 2002; Rollins, 2001).

Coordination at all levels. Weinberger (2002) identified general coordination problems associated with multidimensional peacekeeping. These challenges include divergent organisational culture, different approaches and content for training professionals, ambiguous mandates and insufficient resources for implementation. A comprehensive approach should be followed during the drafting of an all-inclusive plan for all implementation levels. This plan is finalised after the analysis of the crisis and identification of capabilities, role and responsibilities.

\section{Closing the gap between the humanitarian and military view}

Military action is a last resort option that is primarily guided by humanitarian purpose. It is conducted to maximise respect for international human 
rights law and intends to achieve more good than harm (Burckle, 2006). The literature reflects that both the military and the humanitarian community acknowledge the need for cooperation and coordination. Support to the affected population will be significantly more effective if cooperation is enhanced by the humanitarian component (Siegel, 2001). The OIOS identified the need to establish standard operating procedures to address the coordination challenges and to develop and enhance coordination. These guidelines include:

- interaction with the humanitarian component;

- $\quad$ strategy development and identification of suitable projects;

- $\quad$ project priorities;

- planning, implementation and evaluation of projects;

- $\quad$ project communication strategy;

- identification of and interacting with the identified internal and external role players;

- information analysis and coordination; and

- financial management inclusive of identifying appropriate donor and funding mechanisms (OIOS, 2005).

The main barriers in preventing successful coordination remain organisational cultures relating to the approach towards authority and decisionmaking styles. The military decision-making style is based on the hierarchical topdown approach with clear deadlines and rules of engagement that guide all parts of the structure from senior leadership to the soldiers on the ground. A Code of Conduct and Rules of Engagement direct military actions and non-compliance with these directives can result in legal actions being instituted against perpetrators. The structures of humanitarian components are usually decentralised within a relatively flat authoritative structure. The challenge remains especially at the community project level where development agencies promote collaborative decision-making versus the military component process that is not based on consensus or collaborative working relationships (Jeong, 2005). Training opportunities for mutual beneficial exchange might provide a better understanding of cultural differences. These opportunities include conferences, identification and conducting of joint exercises, training, planning and civil military learning opportunities at educational institutions (Abiew, 2003; George, 2002; Harris \& Dombrowski, 2002).

The humanitarian component has immense experience in dealing with complex emergencies. The military component however has much to gain by interacting with the humanitarian component on local knowledge, technical skills and best practices (Harris \& Dombrowski, 2002). Early engagement at institutional level 
is imperative for removing obstacles in cooperation and coordination. This can be achieved through early development of relationships, joint education and exercises, joint planning sessions, joint training and exchange programmes where the military attends humanitarian learning opportunities and vice versa (Spence, 2002).

The military is often obliged to deploy members with insufficient CIMIC training due to a lack of capacity or ineffective selection criteria (Pollick, 2000). George (2002) referred to the fundamental importance for the military to identify competent members to be trained as mission specialist to conduct CIMIC activities. To address the training gap, the South African DoD approved participation in the development of an African CIMIC Handbook to facilitate the training of CIMIC officers for the Department (ACCORD, 2005). This handbook provides an overview of possible military tasks in a humanitarian setting. These tasks include use of military assets for military assistance, integrated planning, security of the humanitarian community and humanitarian tasks in the absence of a humanitarian coordination structure.

From the discussion on peace support operations, the stressors in peace support operations and civil military coordination, specific roles and functions for the CIMIC officer can be identified.

\section{Roles and functions of a CIMIC officer}

The role of the CIMIC officer is determined by the type of and stage within the mission and should allow for flexibility. It emphasises the need for a flexible officer to function in a participative and consultative management environment. CIMIC officers need to understand the complexities between functioning in a cooperative versus a coexistent framework. The roles and functions of the CIMIC officer are as follows:

- $\quad$ Adviser to military commander (Abiew, 2003; Harris \& Dombrowski, 2002; Pugh, 1998; OIOS, 2005; Spence, 2005)

$\circ \quad$ advises the military on the structure, mandate and operating strategies of humanitarians;

- provides specialist advice on CIMIC during planning processes;

- communicates humanitarian needs within the framework of humanitarian principles and operational goals;

- advises on policy implementation guidelines regarding the use of the military in humanitarian action; 
- advises on the feasibility and impact of community support projects;

- advises on the appropriate channels to follow for authorisation of military humanitarian activities; and

- advises on creating a favourable security environment for humanitarians.

- Adviser to the humanitarian coordinator (Abiew, 2002; Burckle, 2006; Jackson, 2005; Jeong, 2005; Newland \& Meyers, 1999)

- advises humanitarian organisations on the structure, mandate, hierarchy and command and control mechanisms of the military;

- advises the humanitarian component on security matters and emphasises the importance of sharing security-related information;

- provides specialist military assistance to humanitarian components;

- advises on the utilisation of available spare capacity and resources of military; and

○ requests authorisation for the military community support projects.

- Coordination officer (Cockell, 2002; De Coning, 2005; JP, 2003; Pugh, 2001; Weinberger, 2002)

- identifies, establishes and maintains contact with relevant role players;

- defines relevant role players' roles, responsibilities and decisionmaking perimeters to avoid duplication of effort;

- establishes effective coordination mechanisms that enhance flexibility through participative and consultative processes;

- coordinates capabilities of relevant organisations to be complementary;

a attends local meetings and reports on it;

- facilitates the development of comprehensive integrated plans through joint assessments on key objectives; and

- establishes coordinating mechanisms at all levels to enhance coordination.

- $\quad$ Project officer for community support initiatives (Jenny, 2001; Newland \& Meyers, 1999; OIOS, 2005)

establishes and implements standing operating procedures to determine suitable projects; 
$\bigcirc$

$\bigcirc$

$\bigcirc$

establishes and manages coordinating mechanisms to evaluate and prioritise projects;

implements and manages approved community support projects; and

facilitates seamless roll out of projects and handing over of completed projects.

- Training coordinator (George, 2002; Harris \& Dombrowski, 2002; IASC, 2005; Pollick, 2000; Pugh, 1998)

- coordinates awareness training on humanitarian and military operating procedures and principles;

- conducts training on CIMIC policy documents and guidelines;

$\circ \quad$ conducts awareness training promoting humanitarian and military organisational cultural awareness; and

- coordinates training to the military by humanitarians on local knowledge, best practices and technical skills.

To be successful in these roles and functions the CIMIC officer needs superior communication skills, liaison and information management skills, analytic and planning skills in a participative environment, respect for cultural diversity, sensitivity towards organisation culture, including values and principles, mutual respect, understanding and superior interpersonal skills. The roles and functions of the CIMIC officer provide the foundations for defining the competencies of successful CIMIC officers. The behaviours and skills identified in the theoretical discussion are linked to personality theories in defining a psychological profile in the subsequent phase of this study. In phase 2 of this study, the psychological profile is linked to performance criterion for selection.

\section{Conclusion}

The CIMIC officer performs roles and functions within a dynamic and everchanging peace support operations environment. Although the challenges in peace support operations are generic to all peacekeepers, the literature reveals that specialist skills over and above the generic peacekeeping soldier skills are required to perform successful as a CIMIC officer. The discussion on the concept of civil military coordination indicated that these skills are inclusive of skills that enhance the working relationship between the military and humanitarian communities. The literature reveals that successful CIMIC officers are flexible, with superior communication skills, management skills, analytic and planning skills, respect for cultural diversity, sensitivity towards organisation culture, mutual respect, understanding and superior 
interpersonal skills. Initial research highlights the importance of high ego power, low state anxiety and high self-esteem to adjust successfully to the peace support environmental stressors. This discussion provides the foundation for defining a psychological profile for a CIMIC officer. Subsequent research linking the theoretical discussion to personality theories, organisational culture and selection guidelines is essential to identify the electives for a competent CIMIC officer. In the absence of a work and psychological profile, the competent officer is possibly not selected for this critical job.

\section{REFERENCES}

Abiew, F.K. (2003). NGO-Military relations in peace operations. International Peacekeeping, 10(1), 24-39.

Abiew, F.K. \& Keating, T. (2004). Defining a role for civil society. In T. Keating \& W.A. Knight (Eds.), Building sustainable peace (pp. 93-118). Alberta: The University of Alberta Press.

African Centre for the Constructive Resolution of Disputes (ACCORD). (2005). African CIMIC course manual ( $3^{\text {rd }}$ Draft). Durban: ACCORD.

Aning, K., Addo, P., Birikorang, E. \& Sowatey, E. (2004). African commitments to conflict prevention and peacemaking. Accra: African Human Security Initiative.

Bartone, P.T. (1997). American IFOR experience: Stressors in the early deployment period. In J.L. Soeters \& J.H. Rovers (Eds.), HL Arms: Netherlands Annual Review of Military Studies (The Bosnian Experience) (pp. 133-139). The Netherlands.

Bartone, P.T. \& Adler, A.B. (1994). A model for soldier psychological adaption in peacekeeping operations. Paper presented at the $36^{\text {th }}$ Annual Conference of the Military Testing Association, Rotterdam, The Netherlands.

Bolton, E.E. (2005). Traumatic stress and peacekeepers. National Center for PTSD. Retrieved September 2005, 18 from http://www.ncptsd.va.gov.

Bramsen, I., Dirkzwager, M.A. \& Van der Ploeg, H.M. (2000). Predeployment personality traits and exposure to trauma as predictor of posttraumatic stress symptoms: A prospective study of former peacekeepers [Electronic version]. American Journal of Psychiatry, 157, 1115-1119.

Bruwer, N. (2003). The South African peacekeeping experience: A comparative analysis. Unpublished Master's Thesis, University of Stellenbosch, Stellenbosch.

Burckle, F.M. (2006). Complex humanitarian emergencies: A review of epidemiological and response models [Electronic version]. J Postgrad Med, 52(2), 110-115.

Cilliers, J. \& Mills, G. (1999). From peacekeeping to complex emergencies. Johannesburg: SAIIA. 
Cockell, J.G. (2002). Civil military responses to security challenges in peace operations: Ten lessons from Kosovo [Electronic version]. Global Governance. 8(4), 483-502.

Deahl, M., Srinivasan, M., Jones, N., Thomas, J., Nebrett, C. \& Jolly, A. (2000). Preventing psychological trauma in soldiers; The role of operational stress training and psychological debriefing [Electronic version]. British Journal of Medical Psychology, 73, 77-85.

De Coning, C.H. (2005). Civil-military coordination and UN peacebuilding operations. African Journal on Conflict Resolution, 5(2), 89-118.

Durch, W.J., Holt, V.K., Earle, C.E. \& Shanahan, M.K. (2003). The Brahimi report and the future of UN peace operations. Canada: The Henry L Stimson Center.

Furnham, A. \& Taylor, J. (2004). The dark side of behaviour at work. Hampshire: Palgrave MacMillan.

George, J.M. (2002). The politics of peace: the challenge of civil-military cooperation in Somalia [Electronic version]. Policy \& Management Review, 2(2), 1-34.

Hall, C.S., Lindzey, G. \& Campbell, J.B. (1998). Theories of personality. New York: Wiley.

Harris, A. \& Dombrowski, P. (2002). Military collaboration with humanitarian organizations in complex emergencies [Electronic version]. Global Governance, $8(2), 155-178$.

Hatzenbichler, G. (2001). CIMIC in Shirbrig peace operations. International Peacekeeping, 8(1), 117-119.

Heyns, C. (Ed.) (2005). Compendium of key human rights documents of the African Union. Pretoria: Pretoria University Press.

Horey, J., Fallesen, J.J., Morath, R., Cronin, B., Cassella, R., Franks, W. \& Smith, J. (2004). Competency based future leadership requirements. (Army Project Number 20262785A790). Virginia: US Army, Institute for the Behavioural and Social Science.

Hough, M., Du Plessis, A. \& Kruys, G.P.H. (2006). Peace support operations: selected United Nations and African documents. (Ad Hoc Publication 43). Pretoria, South Africa: University of Pretoria, Institute for Strategic Studies.

Inter-Agency Standing Committee (IASC). (2005). United Nations (UN) humanitarian civil-military coordination (CM Coord) concept, Endorsed by the Inter-Agency Standing Committee Working Group $60^{\text {th }}$ Meeting. Rome: IASC.

Jackson, M.G. (2005). A necessary collaboration: NGOs, peacekeepers and credible military force - A case study on Sierra Leone and East Timor. In O.P. Richmond \& H.F. Carey (Eds.) Subcontracting peace, The challenges of NGO peacebuilding (pp. 109-118). Hampshire: Ashgate. 
Jakobsen, P.V. (2000). The emerging consensus on gray area peace operations doctrine: Will it last and enhance operational effectiveness? [Electronic version]. International Peacekeeping, 7(3), 36-56.

Jenkins, L. (2003). A CIMIC contribution to assessing progress in peace support operations [Electronic version]. International Peacekeeping, 10(3), 121-136.

Jenny, J. (2001). Civil military cooperation in complex emergencies: finding ways to make it work [Electronic version]. European Security, 10(2), 23-33.

Jeong, H. (2005). Peacebuilding in post conflict societies. London: Lynne Reiner Publishers.

Joint Publication (JP). (2003). Joint doctrine for Civil Affairs: 3-57.1. United States Military Publications: JP.

Keating, T. \& Knight, W.A. (2004). Building sustainable peace. Alberta: The University of Alberta Press.

Kets de Vries, M.F.R. \& Miller, D. (1986). Personality, culture and organization [Electronic version]. Academy of Management Review, 11(2), 266-279.

Knuth, R. (1999). Sovereignty, globalism and information flow in complex emergencies [Electronic version]. The Information Society, 15, 11-19.

Lautze, S., Learning, J., Raven-Roberts, A., Kent, R. \& Mazurana, D. (2004). Assistance, protection and governance networks in complex emergencies, 364(13). Retrieved February, 15, 2006 from www.thelancet.com.

Lindenberg, M. \& Bryant, C. (2001). Going global, transforming relief and development NGOs. Bloomfield: Kumarian Press.

Litz, B.T. (2004, Mar). Stressors and demands for peacekeeping in Kosovo: predictors of mental health response [Electronic version]. Military Medicine, 169, 198-206.

Michel, P. (2005). The Swedish soldier and general mental health following service in peacekeeping operations. Dissertation presented at the Uppsala University: Uppsala.

Mohamed, S. (2005). From keeping peace to building peace: a proposal for a revitalized United Nations Trusteeship Council [Electronic version]. Columbia Law Review, 105, 809-818.

Munslow, B. \& Brown, C. (1999). Complex emergencies: the institutional impasse [Electronic version]. Third World Quarterly, 20(1), 207-221.

Natsios, A.S. (1995). NGO's and the UN System in complex emergencies: Conflict or cooperation? [Electronic version]. Third World Quarterly, 16(3), 408-416.

Newland, K. \& Meyers, D.W. (1999). Peacekeeping and refugee relief. In J. Whitman (Ed.), Peacekeeping and the UN Agencies (pp. 15-30). London: Frank Cass.

Nuciari, M. (2002). Flexibility towards diversity. New skills for military personnel in PSOS. Paper presented at the Annual Conference 2002 of the Committee on Woman in NATO Forces, Brussels, Belgium. 
Office of Internal Oversight Services (OIOS). (2005). Report of the review of military involvement in civil assistance in peace operations. (A/60/588). New York: OIOS

Orsillo, M., Roemer, L., Litz, B.T., Ehlich, P. \& Freidman, M.J. (1998). Psychiatric symptomatology associated with contemporary peacekeeping: an examination of post-mission functioning among peacekeepers in Somalia. [Electronic version]. Journal of Traumatic Stress, 11(4), 611-625.

Pollick, S. (2000, Autumn). Civil-military cooperation: A new tool for peacekeepers. Canadian Military Journal, 57-63.

Pugh, M. (1998). Military intervention and humanitarian action: trends and issues [Electronic version]. Disasters, 22(4), 339-351.

Pugh, M. (2001). The challenge of civil military relations in international peace operations. Disasters, 25(4), 345-357.

Reimann, K.D. (2006). Up to no good? Recent critics and critiques of NGOs. In O.P. Richmond \& H.F. Carey (Eds.), Subcontracting peace, The challenges of NGO peacebuilding, Hampshire: Ashgate.

Rollins, J.W. (2001). Civil-military cooperation in crises response operations: The implications for NATO. International peacekeeping, 8(1), 122-129.

Rosebush, P.A. (1998). Psychological intervention with military personnel in Rwanda [Electronic version]. Military Medicine, 163 (8), 559-563.

Rotberg, R.I., Albaugh, E.A., Bonyongwe, H., Clapham, C., Herbst, J. \& Metz, S. (2000). Peacekeeping and peace enforcement in Africa. Washington DC: Brookings Institution Press.

Salama, P., Spiegel, P., Talley, L. \& Waldman, R. (2004). Lessons learned from complex emergencies over the past decade, 364(13), 1801-1813. Retrieved February, 15, 2006 from www.thelancet.com.

Seybolt, T.B. (1996, December). The myth of neutrality [Electronic version]. Peace Review, 8(4) 521-527.

Shigemura, J. \& Nomura, S. (2002). Mental health issue of peacekeeping workers [Electronic version]. Psychiatry and Clinical Neuroscience, 56, 483-491.

Siegel, A.B. (2001) Associated development projects with military operations: lessons from NATO's first year in BiH. International Peacekeeping, 8(3), 99-114.

Spence, N. (2002). Civil-military cooperation in complex emergencies: more than a field application. International Peacekeeping, 9(1), 165-171.

Stanley, C.H.K. (2003). Psychological dimensions of peacekeeping: the role of the organization [Electronic version]. Journal of the Singapore Armed Forces, 29 (2), 14-21.

United Nations Department of Peacekeeping Operations (UN DPKO). (2002). Civil military coordination policy. New York: UN DPKO. 
United Nations Department of Peacekeeping Operations (UN DPKO). (2003). Handbook on United Nations multidimensional peacekeeping operations. New York: UN DPKO.

United Nations Office for the Coordination of Humanitarian Affairs (OCHA). (2004). Civil military relations in complex emergencies, An IASC reference paper. Geneva: OCHA.

Van Dyk, G.A.J. (1998, September). Peacekeeping psychology: A model for members of military forces and their dependants during peacekeeping operations. Paper presented at the Conference of the International Peace and Security: The African Experience, Saldanha, South Africa.

Vogelaar, A.L.W., Soeters, J.L. \& Born, J.B.G. (1997). Working and living in Bosnia: Experiences of Dutch IFOR soldiers. In J.L. Soeters \& J.H. Rovers (Eds.) $H L$ Arms: Netherlands annual review of military studies (The Bosnian Experience) (pp. 113-127). The Netherlands.

Weinberger, N. (2002). Civil-military coordination in peacebuilding: The challenges in Afghanistan [Electronic version]. Journal of International Affairs, 55(2) 245274.

Williams, R. (1999). Challenges for South and Southern Africa towards nonconsensual peace missions? In J. Cilliers \& G. Mills (Eds.), From peacekeeping to complex emergencies: Peace support missions in Africa (pp. 153-174). Johannesburg: The South African Institute of International Affairs. 